\title{
Evaluation of an enhanced recovery protocol on patients having radical cystectomy for bladder cancer
}

Bonnie Liu ${ }^{1}$; Trustin Domes ${ }^{2}$; Kunal Jana ${ }^{2}$

${ }^{1}$ School of Medicine; ${ }^{2}$ Department of Urology; University of Saskatchewan, Saskatoon, SK, Canada

Cite as: Can Urol Assoc J 2018 July 31; Epub ahead of print. http://dx.doi.org/10.5489/cuaj.5273

Published online July 31, 2018

$* * *$

Abstract

Introduction: Enhanced recovery after surgery (ERAS) protocols are multimodal perioperative care protocols that are designed to shorten recovery time and reduce complication rates. ${ }^{1,2}$ An ERAS protocol was implemented in the Saskatoon Health region for radical cystectomy patients in 2013. This study evaluates the safety and efficacy of the protocol for patients having radical cystectomy for bladder cancer.

Methods: Length of stay, early in-hospital complication rates, 30-day readmission rates, age, and gender were collected for patients seen for bladder cancer requiring radical cystectomy in Saskatoon between January 2007 and December 2016. Of these patients, 176 were pre-ERAS implementation (control group) and 84 were post-ERAS implementation (experimental group). The data from each variable was compared between the groups using a Z-test.

Results: There was no significant difference in age or gender of patients between the groups. Average length of stay pre-ERAS was $14.25 \pm 14.57$ days, which is significantly longer than the post-ERAS average of $10.91 \pm 8.56$ days $(p=0.043)$. There was no significant difference in 30-day readmission rate (19.87\% pre-ERAS vs. $19.05 \%$ post-ERAS; $\mathrm{p}=0.873$ ) or complication rate (51.7\% pre-ERAS vs. $46.4 \%$ post-ERAS; $\mathrm{p}=0.425$ ).

Conclusions: The implementation of an ERAS protocol for radical cystectomy reduces length of stay, with no effect on early complication rates or 30-day readmission rates. This indicates that the protocol is safe for patients when compared to previous practices and is an effective means of reducing length of stay. 


\section{Introduction}

Enhanced recovery after surgery (ERAS) protocols are multimodal perioperative care protocols that are designed to reduce surgical stress response and improve health outcomes in surgical patients. ${ }^{1}$ ERAS protocols are designed to shorten recovery time by focusing on key preoperative, operative, and post-operative elements. ${ }^{1,2}$ This includes items such as preoperative counselling, preventing intraoperative hypothermia, optimization of nutrition, and early mobilization. ${ }^{3}$ ERAS protocols were first developed in the 1990s for colorectal cancer surgeries, where they have proven effective in reducing length of stay in-hospital, with varying effects on complication rates. ${ }^{3-5}$ They have also been applied to vascular surgery and thoracic surgery, and more recently have expanded to patients undergoing radical cystectomy procedures. ${ }^{1}$

Radical cystectomies with lymph node dissection are the gold standard treatment for patients with muscle invasive bladder cancer, and are associated with some of the worst morbidity and complications rates of all urological procedures. ${ }^{1,6}$ Patients that require a radical cystectomy are often elderly patients with comorbidities, and could therefore greatly benefit from protocols that reduce surgical complication and stresses. ${ }^{2}$ Due to the relatively recent introduction of ERAS protocols to radical cystectomy procedures, the literature on the effectiveness of ERAS on radical cystectomy outcomes is limited. ${ }^{7}$ Elements of ERAS that are effective for colorectal cancer surgery may not be as effective in bladder cancer surgery. It has been previously suggested that further study is required to determine which elements would be beneficial to include and if the modified ERAS protocols can be equally effective in bladder cancer patients. ${ }^{2}$ Although there is a great deal of variation in the outcomes of ERAS in the context of cystectomy in the current literature, overall, the majority of studies that have been conducted have shown promising results in terms of reduced length of stay and reduced morbidity. $2,7-13$

In 2013, the Saskatoon Health Region implemented its own ERAS protocol, called the Radical Cystectomy/lleal Conduit Clinical Pathway. The protocol was developed through collaboration between anesthesia, urology, home care, enterostomal therapists, physiotherapy, pre-admission nurses, recovery ward nurses, nurse navigators and nurse educators, and pharmacists. It contains 17 of the 22 elements recommended in the ERAS ${ }^{\circledR}$ Society Guidelines (Table 1). ${ }^{2}$ The pathway is under the oversight of a urologist, however the nursing staff can make adjustments and are responsible for documenting adherence to the guidelines.

The primary objective of this study was to evaluate the effectiveness of the Radical Cystectomy/Ileal Conduit Clinical Pathway ERAS protocol, using length of stay, post-operative complications, and 30-day readmission rate parameters.

\section{Methods}

After obtaining ethics exemption (reference REB: BIO-17-11), we retrospectively collected demographic and clinical data for all patients undergoing a radical cystectomy/ileal conduit for bladder cancer between January 2007 to December 2016 in Saskatoon. This generated a cohort of 260 patients (176 patients seen prior to implementation of the pathway and 84 patients seen 
after implementation of the pathway). Age, sex, pathological staging, and primary surgeon was collected for all patients. There was a total of 15 surgeons practicing throughout the duration of the study. Data on length of stay, post-operative complications, and 30-day readmission rate were compiled by the Saskatoon Health Region's Strategic Health Information and Performance Support (SHIPS) data collection agency. Retrospective chart review was conducted to collect data on use of neoadjuvant therapy and epidural use. Although there were no standardized criteria for discharge, as it was at the discretion of the most responsible physician (MRP), it typically involved being able to ambulate, and tolerate adequate nutrition and analgesia.

As there was right skewness of the data, the primary outcomes of length of stay was analyzed using Gamma distribution, where the level of statistical significance was set at alpha $=0.05$ (Figure 1). Demographic information, pathological staging, post-operative complication rates, and 30-day readmission rates between the pre-ERAS and post-ERAS groups were analyzed using a Z-test, where the level of statistical significance was set at $Z=1.96$, alpha $=0.05$ (two-tailed).

\section{Results}

Demographics and cohort characteristics

There was no significant difference in age or gender between the two cohorts. (Table 2) 47.6\% of patients were from the Saskatoon Health Region, and $42.4 \%$ of patients were from more rural areas of Saskatchewan. None of the patients pre-ERAS implementation received neoadjuvant therapy, whereas 16 patients out of 86 of the post-ERAS cohort received neoadjuvant chemotherapy. Data for epidural use prior to ERAS implementation was not available. After ERAS implementation, there were 72 patients out of 86 who received epidurals (83.7\%). There was not always clear documentation for why an epidural was not used, but some documented reasons included spinal deformity, or paraplegia not necessitating epidural use.

234 patients underwent complete lymph node dissection, which involved taking the internal and external iliac lymph nodes and obturator lymph nodes, with the superior limit being the bifurcation of the aorta. 23 patients underwent incomplete lymph node dissection, which was at the discretion of the surgeon. TNM pathological staging showed no significant differences in pre and post-ERAS for stages 0is through $3 b$, however there was a significant difference in pre and post-ERAS $4 \mathrm{~b}$ staging ( 7 patients pre-ERAS vs. 0 patients post-ERAS, $\mathrm{p}=0.007$ ). (Table 3 ) Data on ASA score and pre-operative nutritional status was not available for all patients.

\section{Length of stay}

The mean length of stay prior to ERAS implementation was $14.25 \pm 14.57$ days, with a median of 10 days. The mean length of stay after ERAS implementation was $10.91 \pm 8.56$ days, with a median of 9 days. The mean length of stay prior to ERAS was significantly longer ( $\mathrm{p}=0.043)$.

(Figure 2, Table 4)

Complication rates 
There was no significant difference in early in-hospital complication rates (51.7\% pre-ERAS vs. $46.4 \%$ post-ERAS, $\mathrm{p}=0.425$ ). The most commonly identified complications were ileus, urinary tract infection (UTI), non-UTI infection, and wound dehiscence. There was no significant difference when comparing pre-ERAS and post-ERAS rates for any of the individual complications identified (Table 5).

\section{0-day readmission rates}

In the timeframe of this study, there were 49 readmissions, 35 prior to ERAS implementation, and 16 after implementation. This represents a 30-day readmission rate of $19.87 \%$ and $19.05 \%$ before and after ERAS implementation $(\mathrm{p}=0.873)$. The average readmission rate was 5.5 per year pre-ERAS compared to 4 post-ERAS, representing a non-statistically significant difference $(p=0.104)$. The most common cause of readmission in both cohorts was infection (UTI and nonUTI infection) (Table 6). Causes for readmission are listed in Table 7.

\section{Compliance data}

After implementation of the ERAS protocol in January 2013, all patients undergoing radical cystectomy for bladder cancer were placed on the protocol, representing a $100 \%$ compliance rate.

\section{Discussion}

Adoption of ERAS protocols is slow among urologists, many of whom are not convinced it works, or that there is not enough evidence to support its implementation. ${ }^{14,15}$ However, with the growing body of evidence showing the benefit of ERAS in cystectomy, it is becoming harder to dispute that ERAS results in better patient outcomes. Our study is the first to evaluate ERAS protocols for radical cystectomy in a Canadian context, where our high percentage of patients from a rural setting creates a unique challenge for care, differing from American and European studies. In addition, our series of radical cystectomy patients utilizing an ERAS protocol implements 17 out of 22 ERAS elements, which is the most of any study performed to date, with the added strength of having a $100 \%$ compliance rate. ${ }^{14}$ When compared to a retrospective cohort, we have shown that and an ERAS protocol in this population is effective in reducing LOS, with no change on post-operative complications or readmissions rates. This is consistent with many other studies, although there is a high degree of variation in study outcomes. ${ }^{7}$ Studies by Djaladat et al., Mukhtar et al., Daneshmand et al., and more recently Baack et al., found similar results. ${ }^{5,16-18}$ It is also reassuring to see a downward trend in the complication rates for overall complications, and more specifically for 3 of the most common complications (ileus, non-UTI infections, and wound dehiscence).

The benefits of ERAS are not only confined to LOS, complication rates, and readmission rates. One study found that it also had a positive effect on emotional function, resulted in less fatigue, and better cognitive and physical functioning at discharge. ${ }^{19}$ The economic impact on the system is another major factor to consider. In the colorectal world, it's been estimated that there 
is a cost savings of $\$ 6,900$ per patient who undergoes ERAS compared to traditional perioperative orders. ${ }^{1}$ Furthermore, it's been shown that even though patients are getting discharged out into the community more quickly, the costs are not transferred into the community in the form of more emergency room or practitioner visits, and do not result in a lower quality of life. ${ }^{1}$ In fact, medical and indirect non-medical costs were significantly lower in areas where ERAS was implemented. ERAS can also greatly reduce variation between institutions by providing a standardized care plan for patients, which may be another factor affecting LOS. ${ }^{7,20}$ In the UK, some institutions report a 3-fold variation in LOS, with the longest average LOS being 29 days. ${ }^{13}$ As there are a multitude of factors at play in ERAS implementation, it is difficult to identify specific elements that affect LOS; it is possible that the decrease in LOS is also due to standardization in practice and documentation in addition to the intervention itself.

The challenge becomes then, what elements of ERAS to include, as not all ERAS guideline recommendations, originally intended for colorectal surgery, may have a beneficial effect for cystectomy patients. Many studies lack information regarding elements of ERAS included, and compliance with the elements. ${ }^{21}$ Even when included, due to the multivariate and complex nature of these pathways, it is very difficult to assess the individual contribution of each element of ERAS to the overall outcome. ${ }^{8}$ While there are studies that look at individual ERAS elements in the context of cystectomies, such as chewing gum ${ }^{22}$ or the use of non-opioid vs. opioid analgesics, ${ }^{23}$ most of the reasoning behind elements included in ERAS are either from studies done in colorectal surgery, or based on physiological reasoning. $3.7,10,12,14,20,24,25$

Only a minority of ERAS for radical cystectomy studies have protocols that implement more than half of the recommended principles, and no studies have implemented all 22 ERAS elements. ${ }^{2,14}$ Although the systematic review by Nicholson et al. found that including more elements does not always translate into better outcomes, ${ }^{8}$ there is no evidence in the literature to suggest that any of the elements included in the Radical Cystectomy/Ileal Conduit Clinical Pathway would be detrimental to cystectomy patients. ${ }^{2,3}$ With regards to the 5 elements omitted from our pathway, the evidence for omitting the pelvic drain is weak, and based on colorectal surgery evidence; in cystectomies, the risk of urinary leak may be higher, and thus having the drain may be beneficial. ${ }^{3}$ Similarly, leaving a urethral drain may be beneficial in colorectal cancer, but is not necessary in cystectomy patients. Our center does not routinely perform laparoscopic cystectomies, and the evidence in favour of robot assisted cystectomy is still in the trial phase. There may be a role for having standardized protocols for perioperative anesthesia, however in Saskatoon, there is a lack of consensus from anesthesiologists on how anesthetics are delivered. Similarly, a lack of consensus from MRPs on nausea and vomiting medications is also a barrier to a standardized nausea and vomiting prophylaxis protocol. These two areas merit further exploration by the ERAS protocol team, with the hopes that standardized protocols can be implemented at our center.

Other future directions include exploring different analgesic methods, increased education with healthcare staff, and the use of drugs such as alvimopan. Studies have shown the 
benefits of rectus sheath blocks over epidurals, the benefits that alvimopan can have on LOS and time to flatus, and improvements in outcomes with increase healthcare staff education. ${ }^{13,14,23}$ Having a pathway with $100 \%$ compliance allows for potentially randomized-controlled trials looking at specific elements such as these.

\section{Limitations}

One of the major limitations of this study is that it is a retrospective study, comparing a more current cohort of patients with a historical group. This may be problematic as the culture around patient-centered care and outcomes has shifted. Additionally, there is no documentation showing which elements of ERAS may have already been practiced prior to official implementation of ERAS. There is also the added consideration of number and skills of surgeons involved, techniques and technology that are improving, and changes in treatment practices over time. For example, neoadjuvant therapy is being adopted more frequently, particularly after implementation of ERAS protocols, and the impact of neoadjuvant therapy on outcomes is not fully known. Similarly, epidural use for pain control was very common in our protocol, but the rates of epidural use prior to ERAS implementation is unknown. The retrospective nature of the study also limited data collection for factors such as pre-op nutritional status and ASA score, or post-operative oral intake and first day of stool passage, which was not always recorded in the charts. Furthermore, the study is non-randomized, although a randomized control trial of ERAS as a whole in the present day would nearly impossible, and possibly unethical given the body of evidence in favour of ERAS. Finally, much of the data was only available through the provincial database, limiting the availability and form of some of the data. For example, only 30-day readmission rates were available, although it is known that 90-day readmission rates are a better reflection of long-term outcomes of ERAS. This also limited classification of complications using commonly used methods such as Clavian Dindo scoring.

\section{Conclusion}

Our study adds to the growing body of evidence showing that ERAS protocols decrease length of stay. The implementation of an ERAS protocol for cystectomy has no effect on early postoperative complication rates or 30-day readmission rates when compared to previous practices, indicating that the protocol is safe for patients while being an effective means of reducing length of stay. Further consideration needs to be given to assessing the benefits of specific ERAS elements in the setting of radical cystectomy, as further data will direct adjustments made to the Radical Cystectomy/Ileal Conduit Clinical Pathway. Reducing length of stay may translate into improved patient outcomes and decreased healthcare system costs, which may be an area of further research. 


\section{References}

1. Melnyk M, Casey RG, Black P, et al. Enhanced recovery after surgery (ERAS) protocols: Time to change practice? Can Urol Assoc J 2011;5:342-48.

2. Patel HRH, Cerantola Y, Valerio M, et al. Enhanced recovery after surgery: Are we ready, and can we afford not to implement these pathways for patients undergoing radical cystectomy? Eur Urol 2014;65:263-66.

3. Cerantola Y, Valerio M, Persson B, et al. Guidelines for perioperative care after radical cystectomy for bladder cancer: Enhanced Recovery After Surgery (ERAS®) society recommendations. Clin Nutr 2013;32:879-87.

4. Kehlet H. Multimodal approach to control postoperative pathophysiology and rehabilitation. Br J Anaesth 1997;78:606-17.

5. Djaladat H, Katebian B, Bazargani ST, et al. 90-Day complication rate in patients undergoing radical cystectomy with enhanced recovery protocol: A prospective cohort study. World J Urol October 2016:1-5.

6. Alfred Witjes J, Lebret T, Compérat EM, et al. Updated 2016 EAU Guidelines on muscleinvasive and metastatic bladder cancer. Eur Urol 2017;71:462-75.

7. Tyson MD, Chang SS. Enhanced recovery pathways versus standard care after cystectomy: A meta-analysis of the effect on perioperative outcomes. Eur Urol 2016;70:995-1003.

8. Nicholson A, Lowe MC, Parker J, et al. Systematic review and meta-analysis of enhanced recovery programmes in surgical patients. Br J Surg 2014;101:172-88

9. Arumainayagam N, McGrath J, Jefferson KP, et al. Introduction of an enhanced recovery protocol for radical cystectomy. BJU Int 2008;101:698-701.

10. Mir MC, Zargar H, Bolton DM, et al. Enhanced Recovery After Surgery protocols for radical cystectomy surgery: review of current evidence and local protocols. ANZ J Surg 2015;85:514-20.

11. Dutton TJ, Daugherty MO, Mason RG, et al. Implementation of the Exeter Enhanced Recovery Programme for patients undergoing radical cystectomy. BJU Int 2014;113:71925.

12. Guan X, Liu L, Lei X, et al. A comparative study of fast-track versus [corrected] conventional surgery in patients undergoing laparoscopic radical cystectomy and ileal conduit diversion: Chinese experience. Sci Rep 2014;4:6820.

13. Smith J, Meng ZW, Lockyer R, et al. Evolution of the Southampton Enhanced Recovery Programme for radical cystectomy and the aggregation of marginal gains. BJU Int August 2014;114:375-83

14. Danna BJ, Wood EL, Baack Kukreja JE, et al. The future of enhanced recovery for radical cystectomy: Current evidence, barriers to adoption, and the next steps. Urology 2016;96:62-8. 
15. Baack Kukreja, JE; Messing, EM; Shah JB. Are we doing “better”? The discrepancy between perception and practice of enhanced recovery after cystectomy principles among urologic oncologists. Urol Oncol Semin Orig Investig 2016;34:120.e17-120.e21.

16. Mukhtar S, Ayres B, Issa R, et al. Challenging boundaries: an enhanced recovery programme for radical cystectomy. Ann R Coll Surg Engl 2013;95:200-06.

17. Baack Kukreja JE, Kiernan M, Schempp B, et al. Quality improvement in cystectomy care with enhanced recovery (QUICCER) study. BJU Int 2017;119:38-49.

18. Daneshmand S, Ahmadi H, Schuckman AK, et al. Enhanced recovery protocol after radical cystectomy for bladder cancer. J Urol 2014;192:50-5.

19. Karl A, Buchner A, Becker A, et al. A new concept for early recovery after surgery for patients undergoing radical cystectomy for bladder cancer: Results of a prospective randomized study. J Urol 2014;191:335-40.

20. Smith J, Pruthi RS, Mcgrath J. Enhanced recovery programmes for patients undergoing radical cystectomy. Nat Rev Urol 2014;11:437-44.

21. Varadhan KK, Neal KR, Dejong CHC, et al. The enhanced recovery after surgery (ERAS) pathway for patients undergoing major elective open colorectal surgery: A meta-analysis of randomized controlled trials. Clin Nutr 2010;29:434-40.

22. Koupparis A, Dunn J, Gillatt D, et al. Improvement of an enhanced recovery protocol for radical cystectomy. Br J Med Surg Urol 2010;3:237-40.

23. Xu W, Daneshmand S, Bazargani ST, et al. Postoperative pain management after radical cystectomy: Comparing traditional versus enhanced recovery protocol pathway. J Urol 2015;194:1209-13.

24. Azhar RA, Bochner B, Catto J, et al. Enhanced recovery after urological surgery: A contemporary systematic review of outcomes, key elements, and research needs. Eur Urol 2016;70:176-87.

25. Aning J, Neal D, Driver A, et al. Enhanced recovery: From principles to practice in urology. BJU Int 2010;105:1199-201. 


\section{Figures and Tables}

Fig. 1. There was a right skewness in length of stay in both the pre-ERAS and post-ERAS cohorts (skewness of 4.25 and 1.91, respectively). ERAS: enhanced recovery after surgery.

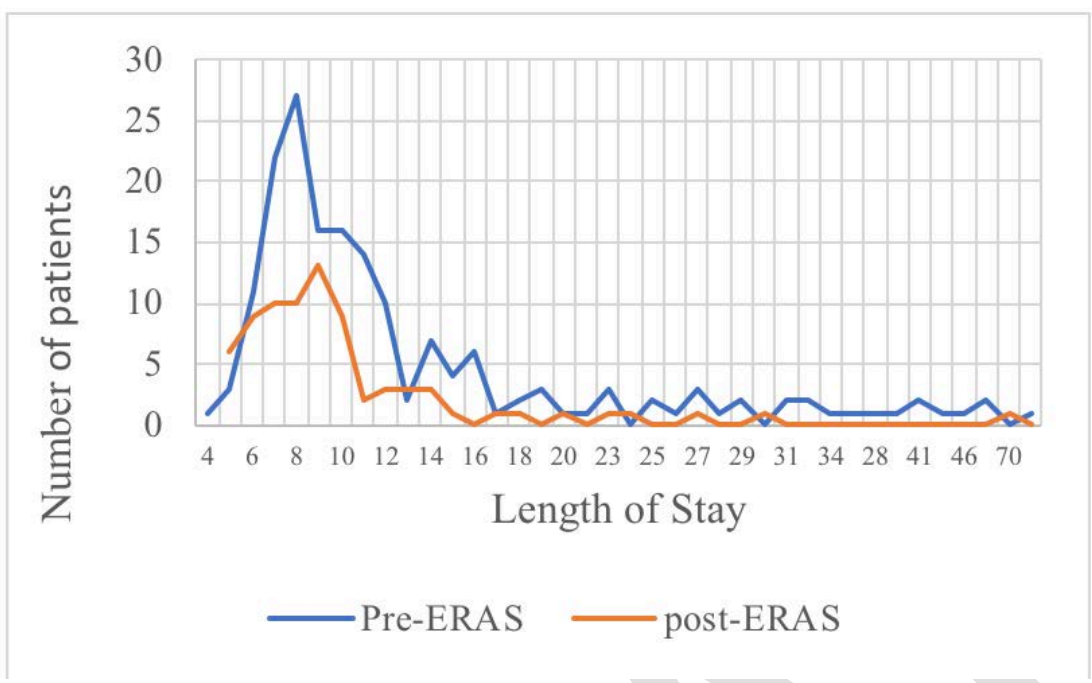

Fig. 2. There was a significant difference in mean length of stay when comparing pre-ERAS implementation cohorts with post-ERAS $(14.25 \pm 14.57$ days vs. $10.91 \pm 8.56$ days, respectively; $\mathrm{p}=0.043)$. ERAS: enhanced recovery after surgery.

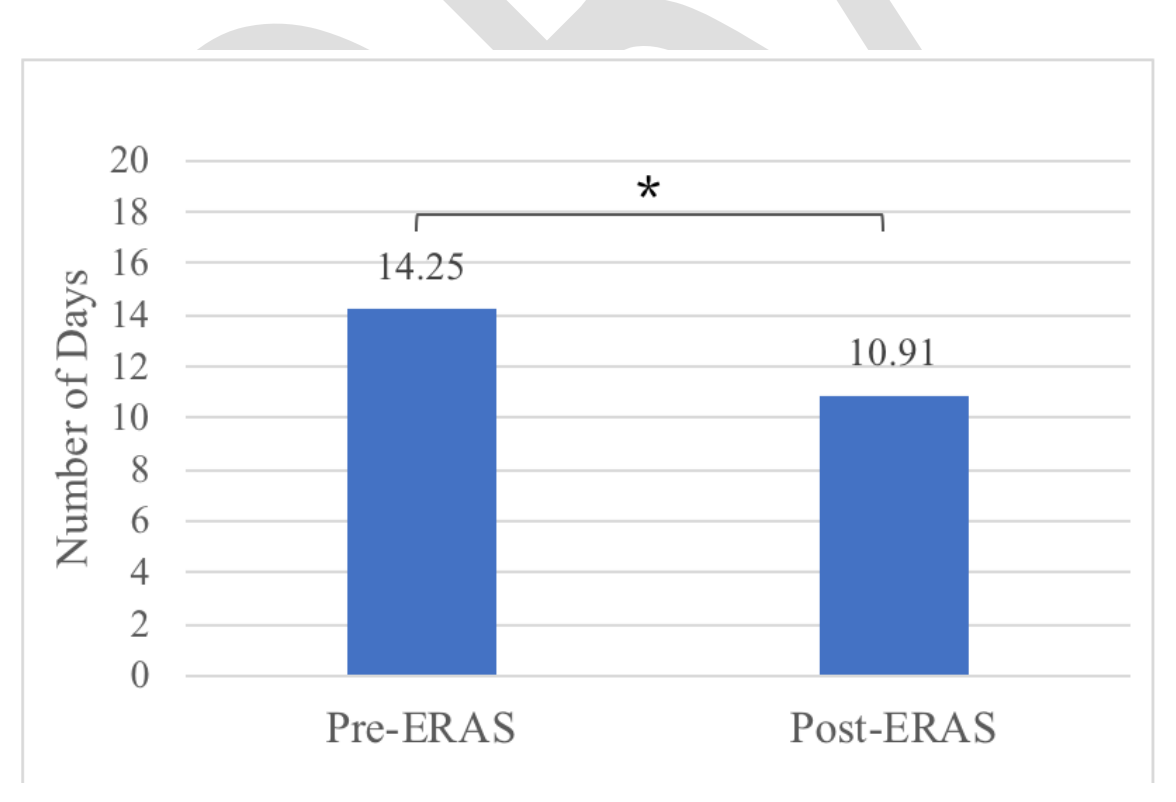




\begin{tabular}{|c|c|c|}
\hline ERAS element & Summary & $\begin{array}{l}\text { ERAS }^{\circledR} \text { society } \\
\text { grade of } \\
\text { recommendation }\end{array}$ \\
\hline \multicolumn{3}{|c|}{ Included elements } \\
\hline $\begin{array}{l}\text { 1. Preoperative } \\
\text { counselling and } \\
\text { education }\end{array}$ & $\begin{array}{l}\text { Patients meet with a nurse navigator and urologist } \\
\text { prior to procedure to receive counselling on } \\
\text { procedure and manage expectations }\end{array}$ & Strong \\
\hline 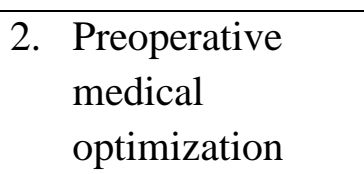 & $\begin{array}{c}\text { Includes elements such as smoking cessation, } \\
\text { weight loss or gain as required, control of } \\
\text { comorbidities }\end{array}$ & Strong \\
\hline $\begin{array}{l}\text { 3. Oral mechanical } \\
\text { bowel } \\
\text { preparation }\end{array}$ & $\begin{array}{l}\text { Traditional bowel preparation prior to surgery is } \\
\text { no longer required }\end{array}$ & Strong \\
\hline $\begin{array}{l}\text { 4. Preoperative } \\
\text { carbohydrate } \\
\text { loading }\end{array}$ & $\begin{array}{l}\text { Increased intake of carbohydrates prior to surgery } \\
\text { in non-diabetic patients }\end{array}$ & Strong \\
\hline $\begin{array}{l}\text { 5. Preoperative } \\
\text { fasting }\end{array}$ & $\begin{array}{l}\text { Solid foods are allowed up to } 6 \text { hours prior to } \\
\text { general anesthesia, and clear fluids allowed up to } \\
2 \text { hours prior }\end{array}$ & Strong \\
\hline $\begin{array}{l}\text { 6. Thrombosis } \\
\text { prophylaxis }\end{array}$ & $\begin{array}{l}\text { Pharmacologic prophylaxis with LMWH prior to } \\
\text { surgery, compression stocking use, and extended } \\
\text { prophylaxis post-surgery as indicated based on } \\
\text { patient risk }\end{array}$ & Strong \\
\hline $\begin{array}{l}\text { 7. Epidural } \\
\text { analgesic }\end{array}$ & $\begin{array}{l}\text { Thoracic epidural placement prior to surgery for } \\
\text { pain management in lieu of increased opioid use }\end{array}$ & Strong \\
\hline $\begin{array}{l}\text { 8. Antimicrobial } \\
\text { prophylaxis and } \\
\text { skin preparation }\end{array}$ & $\begin{array}{l}\text { Single dose of antimicrobial prophylaxis } 1 \text { hour } \\
\text { prior to skin incision, and skin preparation with } \\
\text { chlorhexidine-alcohol preparation }\end{array}$ & Strong \\
\hline $\begin{array}{l}\text { 9. Perioperative } \\
\text { fluid } \\
\text { management }\end{array}$ & $\begin{array}{l}\text { Fluid balance optimization using cardiac output as } \\
\text { a guide to avoid over- and dehydration. }\end{array}$ & Strong \\
\hline $\begin{array}{l}\text { 10. Preventing } \\
\text { intraoperative } \\
\text { hypothermia }\end{array}$ & $\begin{array}{l}\text { Maintain normal body temperature during and } \\
\text { postoperatively with warmed fluids and forced air } \\
\text { patient warming }\end{array}$ & Strong \\
\hline $\begin{array}{l}\text { 11. Nasogastric } \\
\text { intubation }\end{array}$ & $\begin{array}{c}\text { Avoid the use of postoperative nasogastric } \\
\text { intubation }\end{array}$ & Strong \\
\hline
\end{tabular}




\begin{tabular}{|c|c|c|}
\hline $\begin{array}{l}\text { 12. Prevention of } \\
\text { postoperative } \\
\text { ileus }\end{array}$ & $\begin{array}{l}\text { Optimize gastrointestinal function through a } \\
\text { multimodal approach, including oral magnesium, } \\
\text { chewing gum, and early mobilization }\end{array}$ & Strong \\
\hline $\begin{array}{l}\text { 13. Postoperative } \\
\text { analgesia }\end{array}$ & $\begin{array}{l}\text { Post-operative analgesia including thoracic } \\
\text { epidural and oral medication for breakthrough } \\
\text { pain }\end{array}$ & Strong \\
\hline $\begin{array}{l}\text { 14. Early } \\
\text { mobilization }\end{array}$ & $\begin{array}{l}\text { Patients should be encouraged to mobilize } \\
\text { immediately after surgery }\end{array}$ & Strong \\
\hline 15. Early oral diet & $\begin{array}{c}\text { Oral nutrition to be initiated on postoperative day } \\
0\end{array}$ & Strong \\
\hline $\begin{array}{l}\text { 16. Pre-anaesthesia } \\
\text { medication }\end{array}$ & Avoid the use of long acting sedatives & Strong \\
\hline 17. Audit & Monitoring for compliance with ERAS protocol & Strong \\
\hline \multicolumn{3}{|l|}{ Excluded elements } \\
\hline $\begin{array}{l}\text { 18. Minimally } \\
\text { invasive } \\
\text { approach }\end{array}$ & Use of laparoscopic/robotic technique & Strong \\
\hline $\begin{array}{l}\text { 19. Resection site } \\
\text { drainage }\end{array}$ & $\begin{array}{l}\text { Omission of the use of perianastomotic and/or } \\
\text { pelvic drain }\end{array}$ & Weak \\
\hline $\begin{array}{l}\text { 20. Standard } \\
\text { anesthetic } \\
\text { protocol }\end{array}$ & $\begin{array}{l}\text { Anesthetic protocols in place to ensure } \\
\text { hemodynamic stability, muscle relaxation, proper } \\
\text { anesthesia depth, appropriate analgesia }\end{array}$ & Strong \\
\hline 21. Urinary drainage & $\begin{array}{l}\text { Removal of transurethral catheter on postoperative } \\
\text { day } 1 \text { after pelvic surgery in patients with low risk } \\
\text { of urinary retention }\end{array}$ & Weak \\
\hline $\begin{array}{l}\text { 22. Prevention of } \\
\text { postoperative } \\
\text { nausea and } \\
\text { vomiting }\end{array}$ & $\begin{array}{l}\text { Prophylactic multimodal approach to prevent } \\
\text { nausea and vomiting in patients at risk }\end{array}$ & Strong \\
\hline
\end{tabular}

ERAS: enhanced recovery after surgery; LMWH: low molecular weight heparin. 
Table 2. Demographics

\begin{tabular}{|l|c|c|c|}
\hline & Pre-ERAS & Post-ERAS & p \\
\hline Age & 67.84 & 68.9 & $0.449^{*}$ \\
\hline Male (\%) & 72.16 & 82.14 & $0.063^{+}$ \\
\hline
\end{tabular}

* The difference in age was non-significant ( $\mathrm{p}>0.05) .{ }^{+}$The difference in proportion of males was non-significant ( $p>0.05$ ). ERAS: enhanced recovery after surgery.

\begin{tabular}{|l|c|c|c|}
\hline \multicolumn{4}{|l|}{ Table 3. Pathological staging } \\
\hline & Pre-ERAS & Post-ERAS & p \\
\hline $\begin{array}{l}\text { Complete lymph } \\
\text { node dissection (\%) }\end{array}$ & 92.05 & 89.29 & $0.484^{*}$ \\
\hline Stage 0is & 13.64 & 17.86 & $0.391^{+}$ \\
\hline Stage 1 & 11.36 & 10.71 & $0.875^{+}$ \\
\hline Stage 2 & 22.16 & 15.48 & $0.184^{+}$ \\
\hline Stage 3a & 32.95 & 39.29 & $0.323^{+}$ \\
\hline Stage 3b & 15.91 & 16.67 & $0.878^{+}$ \\
\hline Stage 4a & 0 & 0 & 0 \\
\hline Stage 4b & 0.040 & 0 & 0.007 \\
\hline
\end{tabular}

* The difference in completed (vs. incomplete) lymph node dissection was non-significant ( $>>0.05) .{ }^{+}$The difference in pathological TNM staging was non-significant $(\mathrm{p}>0.05)$. Staging based on National Comprehensive Cancer Network (NCCN) TNM Staging system for bladder cancer guidelines.

\begin{tabular}{|l|c|c|c|}
\hline \multicolumn{4}{|c|}{ Table 4. Mean LOS (days), calculated based on gamma distribution } \\
\hline & Pre-ERAS & Post-ERAS & p \\
\hline Mean LOS & 14.25 & 10.91 & 0.043 \\
\hline
\end{tabular}

ERAS: enhanced recovery after surgery; LOS: length of stay. 


\begin{tabular}{|l|c|c|c|}
\hline Table 5. Complication rate \\
\hline Complication & Pre-ERAS rate (\%) & Post-ERAS rate (\%) & p \\
\hline Overall & 51.7 & 46.4 & $0.425^{*}$ \\
\hline Ileus & 27.8 & 20.2 & $0.17^{*}$ \\
\hline Infection - non-UTI & 10.2 & 7.1 & $0.394^{*}$ \\
\hline Infection - UTI & 2.3 & 6.0 & $0.192^{*}$ \\
\hline Dehiscence & 6.3 & 4.8 & $0.614^{*}$ \\
\hline
\end{tabular}

"The difference in complication rates was non-significant ( $p>0.05$ ). ERAS: enhanced recovery after surgery; UTI: urinary tract infection.

\begin{tabular}{|l|c|c|c|}
\hline Table 6. 30-day readmission rate & Pre-ERAS & Post-ERAS & p \\
\hline & 19.87 & 19.05 & $0.873^{*}$ \\
\hline Readmission rate (\%) & 5.5 & 4 & $0.104^{+}$ \\
\hline $\begin{array}{l}\text { Average number of readmitted patients per } \\
\text { year }\end{array}$ & & & \\
\hline
\end{tabular}

${ }^{*}$ The difference in readmission rates was non-significant ( $\left.>>0.05\right) .{ }^{+}$The difference in average number of readmitted patients per year was non-significant ( $\mathrm{p}>0.05)$. ERAS: enhanced recovery after surgery.

\begin{tabular}{|l|c|}
\hline Table 7. Causes for readmission & Number of cases \\
\hline Cause for readmission & 9 \\
\hline UTI & 7 \\
\hline Non-UTI cause of infection & 7 \\
\hline Sepsis & 6 \\
\hline Ileus & 4 \\
\hline Acute renal failure & 3 \\
\hline Malaise and fatigue & 3 \\
\hline Tubule-interstitial nephritis & 2 \\
\hline Dehydration & 8 \\
\hline Other & 49 \\
\hline Total & 2 \\
\hline Compled recovery atter
\end{tabular}

Compiled causes for readmission for pre- and post-ERAS. ERAS: enhanced recovery after surgery; UTI: urinary tract infection. 